\title{
Risperidone-Induced Leukopenia in a Patient with Epilepsy and Sjögren's Synd- rome: A Case Report
}

\section{Yi-Chun Liu*}

Taichung Hospital, Ministry of Health and Welfare, Taichung, Taiwan

${ }^{*}$ Corresponding author: Dr Yi-Chun Liu, Taichung Hospital, Ministry of Health and Welfare, Taichung City 199,sec. 1,San-Min Road, Taichung, Taiwan Tel.: +886-4-22294411; Fax: +886-4-22229517 E-mail address: purpplewhale@yahoo.com.tw

Received Date: November 05, 2018 Accepted Date: November 29, 2018 Published Date: December 02, 2018

Citation: Yi-Chun Liu (2018) Risperidone-Induced Leukopenia in a Patient with Epilepsy and Sjögren's Syndrome: A Case Report. Case Reports: Open Access 3: 1-3.

\begin{abstract}
A-39-year-old Taiwanese man with epilepsy for 30 years and Sjögren's syndrome for 3 years was admitted for newly diagnosed psychosis. He developed leucopenia after treatment with risperidone. After risperidone was discontinued, the white blood cell (WBC) count returned to reference values. For improved symptom control, he was rechallenged with a lower dose of risperidone under close monitoring, but the leukopenia redeveloped. After a shift to paliperidone use, the WBC count gradually normalized. When prescribing risperidone, physicians should be aware of its effects on leukopenia.
\end{abstract}

\section{Introduction}

Many second-generation antipsychotics (SGAs) are associated with weight gain, hyperglycemia, and dyslipidemia, and the American Diabetes Association consensus statement recommends regular metabolic monitoring. [1] However, blood dyscrasias is a relatively rare side effect, and a complete blood count and differential count are not routinely examined, except for clozapine. [2] Only a few case reports on other SGAs, such as olanzapine $[3,4]$ quetiapine $[5,6]$ and risperidone $[7,8]$ have related SGAs to leukopenia and neutropenia.

We describe a case of leucopenia and neutropenia during treatment with risperidone, antiepileptics, and lowdose disease-modifying antirheumatic drugs (DMARDs). The neutropenia resolved after the discontinuation of risperidone.

\section{Case report}

A 39-year-old man was admitted to our psychiatric acute ward with a 1-month history of sudden onset auditory hallucinations, referential delusion, and persecutory delusion. He had a history of refractory epilepsy for 30 years and Sjögren's syndrome for 3 years. The Sjögren's syndrome was diagnosed on the basis of the American-European Consensus Criteria [9]. The seizures were mostly simple partial seizures and treated with oxcarbazepine $(1500 \mathrm{mg} / \mathrm{d})$, topiramate $(425 \mathrm{mg} / \mathrm{d})$, levetiracetam $(2500 \mathrm{mg} / \mathrm{d})$, and clonazepam $(3 \mathrm{mg} / \mathrm{d})$ for 2 months. For Sjögren's syndrome, he was treated with hydroxychloroquine $(400 \mathrm{mg} / \mathrm{d})$ and meloxicam $(15 \mathrm{mg} / \mathrm{d})$ for 3 months. He had not taken any antipsychotic medications before hospitalization. 
On admission, the laboratory assessment showed a white blood cell (WBC) count of $4.00 \times 10^{9} / \mathrm{L}$ (normal range: 4.0 to $11.0 \times 10^{9} / \mathrm{L}$ ) and a neutrophil count of $2.05 \times 10^{9} / \mathrm{L}$ (normal range: 1.5 to $8.0 \times 10^{9} / \mathrm{L}$ ). The other cell counts were within the normal ranges. The patient received risperidone at $2 \mathrm{mg}$ on the first day, and the dose was raised to $4 \mathrm{mg}$ on the second day. On day 7, laboratory tests revealed a prominent decrease in the WBC (WBC: $2.61 \times 10^{9} / \mathrm{L}$, neutrophils: $0.99 \times 10^{9} / \mathrm{L}$ ). There were no signs or symptoms of any acute or overwhelming infections.

Additional laboratory tests were conducted for identifying possible causes of the leucopenia and neutropenia. Vitamin B12, lactate dehydrogenase, C3, C4, and reticulocyte counts were within the normal range. Based on the temporality and disease course, side effects of risperidone and oxcarbazepine were considered. We discontinued risperidone and lowered the dosage of oxcarbazepine from 1500 to $1200 \mathrm{mg} / \mathrm{d}$. Three days after risperidone was discontinued and the oxcarbazepine dosage was reduced, the leukopenia improved (WBC:3.53×109/L, neutrophils: $2.05 \times 10^{9} / \mathrm{L}$ ). On day 10 , we raised the oxcarbazepine dosage back to $1500 \mathrm{mg} / \mathrm{d}$ and administered aripiprazole $(30 \mathrm{mg} / \mathrm{d})$. On day 12 , the WBC continued to increase (WBC:4.20 $\times 10^{9} / \mathrm{L}$, neutrophils: $2.66 \times 10^{9} / \mathrm{L}$ ), but the psychotic symptoms responded poorly to aripiprazole. On day 13 , risperidone $(2 \mathrm{mg} / \mathrm{d})$ was substituted for aripiprazole. On day 17 , WBC and neutrophils decreased to $3.23 \times 10^{9} / \mathrm{L}$ and $1.74 \times 10^{9} / \mathrm{L}$, respectively. Paliperidone $(3 \mathrm{mg} / \mathrm{d})$ was administered instead of aripiprazole, and the dose was raised to $9 \mathrm{mg} 3$ days later. The patient's WBC gradually normalized after the antipsychotic switch and remained normal for the rest of the hospitalization period.

\section{Discussion}

In the present case, the patient had normal range of WBC count before antipsychotics treatment. Leukopenia developed after risperidone treatment, and redeveloped after rechallenging with a lower dose. No leukopenia or neutropenia was observed with paliperidone. Based on the chronology of the treatment and the result of the rechallenge, we hypothesize that risperidone induced leukopenia in this patient.

According to previous studies, patients with Sjögren's syndrome are more susceptible to hematological abnormalities than general population. [10-12] these hematological abnormalities are known as autoimmune cytopenia, possibly related with the degree of extra-glandular or glandular organs involvement. [10-12] in this vulnerable population, certain antipsychotics use, especially risperidone, may further elevate the risk of leukopenia.

Although oxcarbazepine is a structural analog of carbamazepine, its association with hematological adverse effects is extremely rare.
Among DMARDs, several drugs affect the hematological system. Hydroxychloroquine has been widely used to treat Sjögren's syndrome and is associated with rare hematologic side effects. The oxcarbazepine and DMARDs were unlikely to control the leukopenia in this patient.

Certain mechanisms of neutropenia induced by psychotropic drugs have been proposed. They include direct toxicity on the bone marrow and the formation of antibodies against hematopoietic precursors and neutrophils [2]. A few cases of risperidone-induced leucopenia and neutropenia $[7,8][13-16]$ and a case of paliperidone-induced leukopenia and neutropenia [17] have been reported. These case reports, except for one, did not report the results of rechallenge. [14] in that one case, the patient had a previous history of clozapinerelated leukopenia, and he redeveloped leukopenia after using risperidone for weeks.

A previous report proposed that risperidone-induced neutropenia may be the direct toxic effect of unstable drug metabolites on circulating neutrophils and/or the bone marrow. [18] Paliperidone, 9-OH-risperiodne, is the primary metabolite of risperidone. In our case, paliperi done following risperidone use was not associated with leukopenia or neutropenia, indicating that risperidone itself may have direct toxic effects on the hematological system. From this case, we recommend that clinicians be aware of the possible effect of risperidone on leukopenia, especially those with susceptibility to hematologic abnormalities. 


\section{References}

1) Consensus development conference on antipsychotic drugs and obesity and diabetes (2004) Diabetes Care. 27:596-601.

2) Rettenbacher MA, Hofer A, Kemmler G and Fleischhacker WW (2010) Neutropenia induced by second generation antipsychotics: a prospective investigation. Pharmacopsychiatry 43:41-4.

3) Duggal HS, Gates C and Pathak PC. (2004) Olanzapine-induced neutropenia: mechanism and treatment. J Clin Psychopharmacol. 24:234-235.

4) Stergiou V, Bozikas VP, Garyfallos G, Nikolaidis N, Lavrentiadis G et.al (2005) Olanzapine-induced leucopenia and neutropenia. Prog Neuropsychopharmacol Biol Psychiatry. 29:992-994.

5) Cowan C and Oakley C. (2007) Leukopenia and neutropenia induced by quetiapine. Prog Neuropsychopharmacol Biol Psychiatry. 31:292-294.

6) Li X and Cameron MD. (2012) Potential role of a quetiapine metabolite in quetiapine-induced neutropenia and agranulocytosis. Chem Res Toxicol. 25:1004-1011.

7) Tseng CC. (2011) Neutropenia during risperidone treatment. The Journal of neuropsychiatry and clinical neurosciences 23: E19.

8) Manfredi G, Solfanelli A, Dimitri G, Cuomo I, Sani G, et.al (2013) Risperidone-induced leukopenia: a case report and brief review of literature. Gen Hosp Psychiatry. 35: 102. e3-6.

9) Vitali C, Bombardieri S, Jonsson R, Moutsopoulos HM, Alexander EL, et.al (2002) Classification criteria for Sjogren's syndrome: a revised version of the European criteria proposed by the American-European Consensus Group. Annals of the rheumatic diseases 61:554-558.

10) Aoki A, Ohno S, Ueda A, Ideguchi H, Ohkubo T, et.al (2000) [Hematological abnormalities of primary Sjogren's syndrome]. Nihon Rinsho Men'eki Gakkai kaishi 23:124-128.

11) Qiao L, Chen J, Leng XM, Zhang W, Han B, et.al (2016) Agranulocytosis and mixed-type autoimmune hemolytic anemia in primary sjogren's syndrome: a case report and review of the literature. Int J Rheum Dis. 19: 1351-1353.

12) Koh JH, Lee J, Chung SH, Kwok SK and Park SH. (2015) Relation of Autoimmune Cytopenia to Glandular and Systemic Manifestations in Primary Sjogren Syndrome: Analysis of 113 Korean Patients. The Journal of rheumatology 42:1817-24.
13) Biswas A, Mittal P, Chaturvedi S and Prasad A. (2000) Risperidone induced cytopenias. The Journal of the Association of Physicians of India 48:1122-1123.

14) Dernovsek $Z$ and Tavcar R. (1997) Risperidone-induced leucopenia and neutropenia. The British journal of psychiatry: the journal of mental science 171:393-394.

15) Sluys M, Guzelcan Y, Casteelen G and de Haan L.(2004) Risperidone-induced leucopenia and neutropenia: a case report. European psychiatry: the journal of the Association of European Psychiatrists 19:117.

16) Uzun S, Kozumplik O, Jakovljevic $M$ and FolnegovicSmalc V. (2008) Leukopenia during therapy with risperidone long-acting injectable: two case reports. Journal of clinical psychopharmacology 28:713-714.

17) Kim JN, Lee BC, Choi IG, Jon DI and Jung MH.(2011) Paliperidone-induced leukopenia and neutropenia: a case report. Progress in neuro-psychopharmacology \& biological psychiatry 35:284-285.

18) Mishra AC and Mohanty B. (2010) Effects of lactational exposure of olanzapine and risperidone on hematology and lymphoid organs histopathology: a comparative study in mice neonates. European journal of pharmacology 634:170-

Submit your manuscript to a JScholar journal and benefit from:

๑ Convenient online submission

ฯ Rigorous peer review

q Immediate publication on acceptance

ฯ Open access: articles freely available online

ब High visibility within the field

- Better discount for your subsequent articles

Submit your manuscript at http://www.jscholaronline.org/submit-manuscript.php 